\title{
In Vitro Bioactivity and Antimicrobial Tuning of Bioactive Glass Nanoparticles Added with Neem (Azadirachta indica) Leaf Powder
}

\author{
M. Prabhu, ${ }^{1}$ S. Ruby Priscilla, ${ }^{1}$ K. Kavitha, ${ }^{1}$ P. Manivasakan, ${ }^{1}$ \\ V. Rajendran, ${ }^{1}$ and P. Kulandaivelu ${ }^{2}$ \\ ${ }^{1}$ Centre for Nanoscience and Technology, K. S. Rangasamy College of Technology, Tiruchengode, Namakkal District, \\ Tamil Nadu 637215, India \\ ${ }^{2}$ Department of Mechanical Engineering, K. S. Rangasamy College of Technology, Tiruchengode, Namakkal District, \\ Tamil Nadu 637215, India \\ Correspondence should be addressed to V. Rajendran; veerajendran@gmail.com
}

Received 6 February 2014; Revised 10 July 2014; Accepted 24 July 2014; Published 7 September 2014

Academic Editor: Kibret Mequanint

Copyright (c) 2014 M. Prabhu et al. This is an open access article distributed under the Creative Commons Attribution License, which permits unrestricted use, distribution, and reproduction in any medium, provided the original work is properly cited.

\begin{abstract}
Silica and phosphate based bioactive glass nanoparticles $\left(58 \mathrm{SiO}_{2}-33 \mathrm{CaO}-9 \mathrm{P}_{2} \mathrm{O}_{5}\right)$ with doping of neem $($ Azadirachta indica) leaf powder and silver nanoparticles were prepared and characterised. Bioactive glass nanoparticles were produced using sol-gel technique. In vitro bioactivity of the prepared samples was investigated using simulated body fluid. X-ray diffraction (XRD) pattern of prepared glass particles reveals amorphous phase and spherical morphology with a particle size of less than $50 \mathrm{~nm}$. When compared to neem doped glass, better bioactivity was attained in silver doped glass through formation of hydroxyapatite layer on the surface, which was confirmed through XRD, Fourier transform infrared (FTIR), and scanning electron microscopy (SEM) analysis. However, neem leaf powder doped bioactive glass nanoparticles show good antimicrobial activity against Staphylococcus aureus and Escherichia coli and less bioactivity compared with silver doped glass particles. In addition, the biocompatibility of the prepared nanocomposites reveals better results for neem doped and silver doped glasses at lower concentration. Therefore, neem doped bioactive glass may act as a potent antimicrobial agent for preventing microbial infection in tissue engineering applications.
\end{abstract}

\section{Introduction}

Bioactive glasses allow controlled reactivity and induce a specific biological response that leads to the formation of a biologically active carbonated hydroxyapatite (HAp) layer which is structurally and chemically equivalent to that of the mineral phase of bone $[1,2]$. Nanostructured bioactive glasses have gained much attention due to their superior osteoconductive properties when compared with conventional (micron sized) bioactive glass materials. The bioactive glass nanoparticles or nanofibers with polymeric systems enable us to develop potential nanocomposites for orthopedic applications to avoid health risks [3]. Generally, the dissolution rate and microbial infection of implants/biomaterials in orthopedic surgery are still critical health concerns. Infections associated with orthopedic surgery are usually caused by Gram-positive organisms such as Staphylococcus aureus, $S$. epidermidis, andstreptococci and Gram-negative organisms such as Escherichia coli, Enterobacter, and Pseudomonas aeruginosa [4].

Recently, bioactive glass nanoparticles doped with antimicrobial agents such as silver, zinc, and magnesium ions have been widely used for clinical applications [5-8]. Similarly, incorporation of metal oxides such as $\mathrm{ZnO}, \mathrm{MgO}$, $\mathrm{Al}_{2} \mathrm{O}_{3}$, and $\mathrm{TiO}_{2}$ into ceramics and glasses is successfully carried out for tissue engineering purposes [8-11]. Sol-gel derived glass systems possess good textural properties and are capable of accelerating HAp layer formation [12, 13]. Metal oxides are widely used as biomaterials, wherein silver is doped to provide antimicrobial properties against bone infection [14, 15]. Even though silver based glasses release silver ions in a controlled manner for treating bacterial 
infection, accumulation of silver in bone material may cause metal toxicity to humans. In addition, elevated silver content in bioactive glass may also result in low dissolution rate while replacing calcium ions, poor mechanical property, and in vitro behavior [7]. The earlier studies show that the higher silver substitution in bioactive glasses leads to the formation of incipient crystallisation of quartz and, hence, reduces biocompatibility of glass samples [16].

To overcome this obstacle, we have made an attempt to develop bioactive glass nanoparticles by incorporating natural organic substances such as neem, which is an excellent natural antimicrobial agent against broad spectrum of bacteria. Neem (Azadirachta indica) is a potent botanical source that has excellent antibacterial, anti-inflammatory, and antiviral properties [17]. The medicinal value of plant is due to the presence of organic/inorganic substances that have a definite physiological action on living organisms. Thus, it is considered as a valuable source of unique natural products for the development of varietal medicines against various diseases and also for the development of industrial products [18]. In this regard, the unique properties of neem have been previously employed for the development of antibacterial polymeric nanocomposite films for food preservative applications [19]. Currently, developing the neem based bioactive glasses and screening for their better in vitro bioactivity and cytotoxicity is being an essential task in order to overcome several clinical infections. Hence, bioactive glass nanoparticles doped with neem powder are expected to have better physicochemical properties along with the wide spectrum of antibacterial properties which leads to developing a unique glass composite biomaterial for biomedical applications.

In this study, the aim is to develop a new nanobiomaterial compound from natural sources like neem with good biological activity. In this regard, the nanobioactive glasses added with neem leaf powders are synthesised via simple solgel method. The efficiency of neem doped glass nanoparticles is compared with base glass and silver doped nanobioactive glass particles for their physicochemical properties. The bioactivity and antimicrobial activity against $S$. aureus and E. coli are explored through systematic studies for tissue engineering applications.

\section{Material and Methods}

2.1. Materials. The bioactive glass $\left(\mathrm{SiO}_{2}-\mathrm{CaO}-\mathrm{P}_{2} \mathrm{O}_{5}\right)$ nanoparticles with $1 \mathrm{~mol} \%$ of silver and neem leaf powder were prepared by sol-gel method [5, 6]. Tetraethyl orthosilicate (TEOS; 99\%; Sigma-Aldrich, India), triethyl phosphate (TEP; 99.5\%; HiMedia, India), calcium nitrate $\left(\mathrm{Ca}\left(\mathrm{NO}_{3}\right)_{2} \cdot 4 \mathrm{H}_{2} \mathrm{O}\right.$; 98\%; Merck, India), silver nitrate (99\%; Merck), $2 \mathrm{~N}$ nitric acid (69\%; Merck), ethanol, $1 \mathrm{M}$ ammonia (25\%; Merck, India), ultrapure water (Arium 611UF; Sartorius AG, India), and neem leaf powder were used for the preparation of bioactive glass nanoparticles.

2.2. Preparation of Neem Leaf Powder. Fresh neem leaves were collected from the Tiruchengode region (Tamil Nadu, India). These leaves were washed several times by double distilled water to remove dust and other impurities and then were shade-dried without exposure to sunlight. The dried leaves were made to ultrafine particles through planetary ball mill (PM100; Retsch, Haan, Germany) in a dry medium at $500 \mathrm{rpm}$ for $3 \mathrm{~h}$. Milling was performed in a $250 \mathrm{~mL}$ zirconia grinding jar with $10 \mathrm{~mm}$ zirconia balls that were used for millings; ball/charge ratio was $20: 1$. After grinding, the fine particles were collected and stored under nitrogen atmosphere to prevent agglomeration. Finally, these fine particles were used to synthesize neem doped bioactive glass nanoparticles.

\subsection{Synthesis of Bioactive Glass Nanoparticles. To prepare} bioactive glass nanoparticles, initially, TEOS was dissolved in $1: 1$ ratio of ethanol and distilled water and then $2 \mathrm{~N}$ nitric acid was added. The solution was then stirred at room temperature for $30 \mathrm{~min}$. After the complete hydrolysis of TEOS, TEP was dropwise added to the stirred precursor and stirring continued for $30 \mathrm{~min}$. Calcium nitrate was dissolved separately with $2 \mathrm{~mL}$ distilled water and this solution was added to silica solution at $30 \mathrm{~min}$ interval under constant stirring at room temperature. After obtaining the clear solution, $1 \mathrm{M}$ ammonia solution was added drop by drop until the formation of gel, that is, until the solution reaches the $\mathrm{pH}$ 8.0. The resulting gel was kept in a hot-air oven at $60^{\circ} \mathrm{C}$ for $48 \mathrm{~h}$ and further dried at $120^{\circ} \mathrm{C}$ for $48 \mathrm{~h}$. The obtained powder was ground and calcined at $500^{\circ} \mathrm{C}$ for $4 \mathrm{~h}$ to remove the carbon and nitrate impurities. Similarly, silver doped glass was produced by repeating the same procedure followed by addition of silver nitrate solution before the addition of $1 \mathrm{M}$ ammonia solution. The prepared nanobioactive glass samples are hereafter termed as NBG (base glass) and as SNBG (silver doped bioactive glass). The prepared bioactive glass nanoparticles and $1 \mathrm{~g}$ fine neem leaf particles were uniformly mixed by planetary ball mill for $15 \mathrm{~min}$. Then, the collected samples were stabilised at $60^{\circ} \mathrm{C}$ for 2 days to remove the moisture and agglomeration. The prepared neem leaf particles doped bioactive glasses nanoparticles are hereafter termed as NNBG.

2.4. Characterisation. The phase analyses of bioactive glass nanoparticles were obtained through X-ray diffraction (XRD) studies using an X-ray diffractometer (X'PertPRO; PANalytical, the Netherlands) with $\mathrm{CuK} \alpha$ as a radiation $(\lambda=$ $1.5418 \AA$ ) at $40 \mathrm{kV}$ with a diffraction angle $(2 \theta)$ varying from $10^{\circ}$ to $80^{\circ}$. The infrared spectra of prepared glasses were measured using Fourier transform infrared (FTIR) spectrometer (Spectrum 100; PerkinElmer, USA) at room temperature in the wavenumber range from 4000 to $400 \mathrm{~cm}^{-1}$. The particle size, shape, and surface morphology of bioactive glass nanoparticles were studied using transmission electron microscopy (TEM; CM 200; Philips, USA) and scanning electron microscopy coupled with an energy-dispersive $\mathrm{X}$ ray analysis (SEM-EDX, JSM 6360; JEOL, Japan). The purity of the prepared bioactive glass nanoparticles was confirmed by X-ray fluorescence spectrometer (XRF; EDX-720; Shimadzu, Japan). The Brunauer-Emmett-Teller (BET) surface area analyser (Autosorb AS-1MP; Quantachrome, USA) was used to determine the specific surface area (SSA). The NBG 
and SNBG samples were degassed for $2 \mathrm{~h}$ at $290^{\circ} \mathrm{C}$ and then physisorption analysis was performed with $\mathrm{N}_{2}$ adsorption and desorption measurements at liquid $\mathrm{N}_{2}$ temperature $\left(-196^{\circ} \mathrm{C}\right)$. In case of NNBG, the sample was degassed for $2 \mathrm{~h}$ at $80^{\circ} \mathrm{C}$ to remove the moisture content.

2.5. In Vitro Bioactivity. The simulated body fluid (SBF) was freshly prepared following the standard protocol [20] using analytical grade chemicals (Merck, India) to explore the in vitro bioactivity of the glass samples. The $\mathrm{pH}$ value of SBF was 7.4, which is equivalent to that of human blood plasma. From the prepared nanobioactive glass powders (NBG, SNBG, and NNBG), $250 \mathrm{mg}$ was made as pellet using hydraulic pellet maker. The pellets were then immersed separately in $50 \mathrm{~mL}$ $\mathrm{SBF}$ and incubated at $37^{\circ} \mathrm{C}$ for 21 days. The ionic changes in the SBF were measured regularly using a pH meter (Orion 5Star; Thermo Scientific, USA) at an interval of $24 \mathrm{~h}$. After 21 days of immersion, the pellets were removed from the SBF, gently washed with distilled water, and then dried in hot-air oven. The weight loss percentage of sample was calculated according to the following equation:

$$
\text { Weight loss }(\%)=\frac{W_{0}-W_{t}}{W_{0}} \times 100,
$$

where $W_{0}$ is the initial weight of the sample and $W_{t}$ is the weight of the sample measured at time $t$ after drying. The above-mentioned experimental procedure was repeated for all samples. After completing the SBF studies, all the prepared pellets were dried at $60^{\circ} \mathrm{C}$. The characterisation studies, such as XRD, FTIR, and SEM analysis, were carried out for all samples (NBG, SNBG, and NNBG) to reveal the formation of HAp layer on the glass surface.

2.6. Antibacterial Activity. The antimicrobial activity of prepared nanobioactive glass particles was tested against clinical pathogens such as $S$. aureus and E. coli using Kirby-Bauer disc-diffusion method [21]. Mueller Hinton agar (MHA) medium (HiMedia, India) was prepared and sterilised at $121^{\circ} \mathrm{C}$ (15 psi). The MHA plates were prepared by pouring $15 \mathrm{~mL}$ molten medium onto sterile Petri plates. The plates were allowed to solidify for about $5 \mathrm{~min}$ and $0.1 \%$ of culture suspension was swabbed uniformly over the agar until it became invisible. NBG, SNBG, and NNBG pellet samples of $10 \mathrm{~mm}$ diameter with $2 \mathrm{~mm}$ thickness were placed separately on the freshly inoculated culture plates. The culture plates were incubated at $37^{\circ} \mathrm{C}$ for $24 \mathrm{~h}$. The diameter of inhibition zones formed around glass disk in all bioactive glass samples was measured in millimeter with a transparent ruler.

2.7. Biocompatibility Study. The cytotoxic responses of the prepared glass nanocomposites were screened at different concentrations against human gastric adenocarcinoma cell line (AGS). AGS cell line (ATCC-1739) was obtained from the National Centre for Cell Science, Pune, India. The cells were grown and maintained in Dulbecco's modified Eagle's medium (DMEM)/nutrient mixture F-12 HAM (1:1) with $2 \mathrm{mML}^{-1}$ glutamine supplemented with $10 \%$ fetal bovine serum, $45 \mathrm{IU} \mathrm{mL}^{-1}$ penicillin, and $45 \mathrm{IU} \mathrm{mL}^{-1}$ streptomycin.

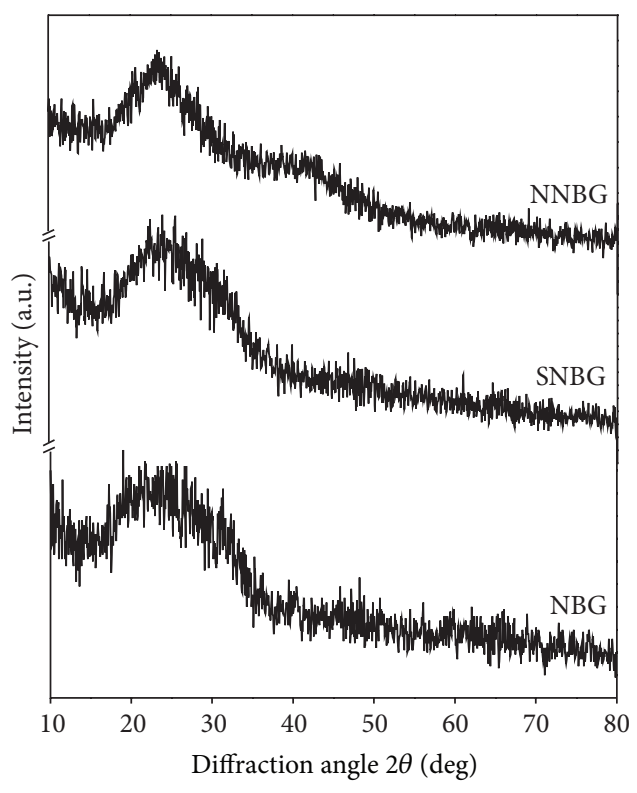

FIGURE 1: XRD pattern of prepared bioactive glass nanocomposites.

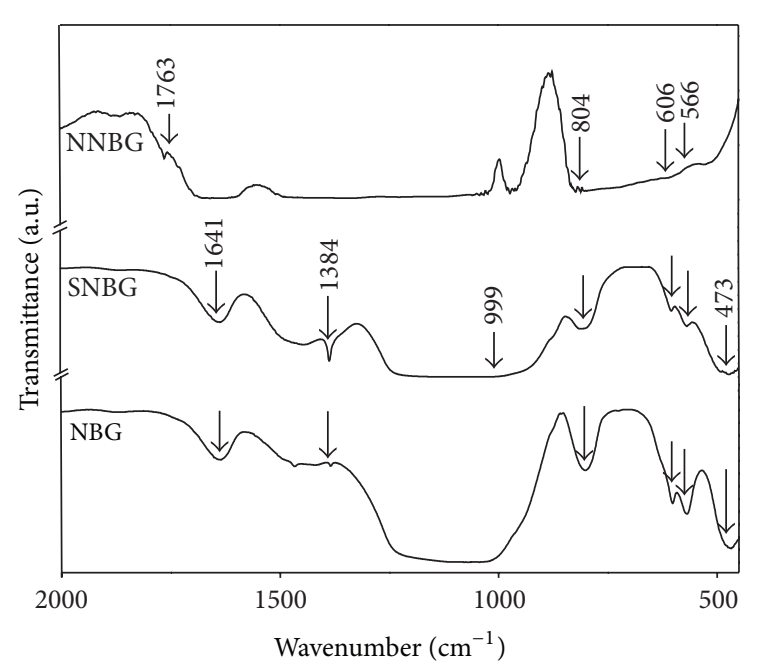

FIGURE 2: FTIR spectra of bioactive glass nanocomposites.

Growth ingredients were also added and incubated in a humidified atmosphere at $37^{\circ} \mathrm{C}$ in $5 \% \quad \mathrm{CO}_{2}$. The morphology of AGS cell lines was observed regularly under binocular inverted microscope. After $48 \mathrm{~h}$ of incubation, MTT (3-(4,5-dimethylthiazol-2-yl)-2,5-diphenyltetrazolium bromide) assay was performed to evaluate the viability of the nanobioactive glass-treated AGS cells. The percentage of cell viability from triplicates of the nanobioactive glass-treated and nontreated cells was calculated using optical density $\left(\mathrm{OD}_{590 \mathrm{~nm}}\right)$ as follows:

$$
\begin{aligned}
\text { Cell viability } \%= & \frac{\mathrm{OD} \text { of the nanoparticles treated cells }}{\text { OD of the cells }} \\
& \times 100 .
\end{aligned}
$$




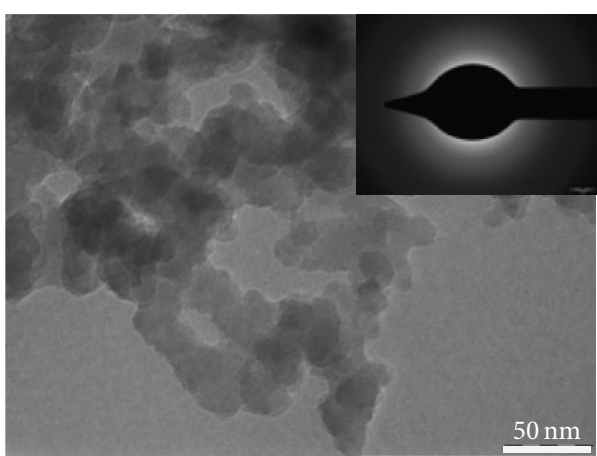

(a) NBG

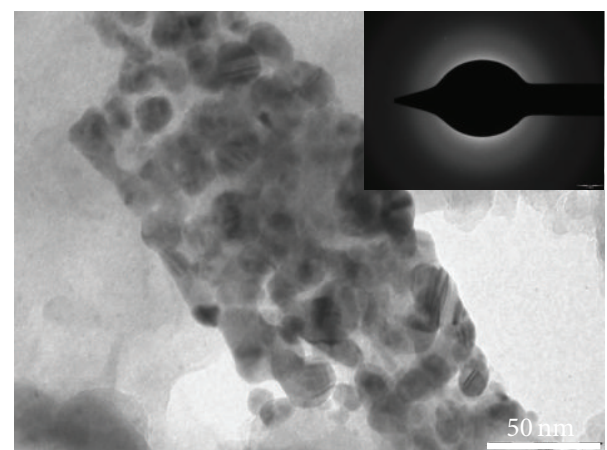

(b) SNBG

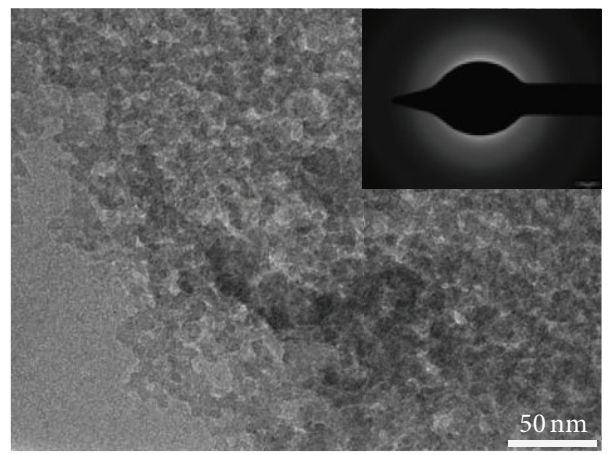

(c) NNBG

FIGURE 3: TEM images of prepared bioactive glass nanoparticles.

\section{Results and Discussion}

The XRD pattern of prepared NBG, SNBG, and NNBG is shown in Figure 1. The observed results confirm that there are no diffraction peaks except for broad band observed at $2 \theta$ values in the range of $20-30^{\circ}$. From the observed results, it is concluded that all glass samples exhibit amorphous nature (JCPDS number 79-1711) without any crystalline peaks and particles reveal that doping of silver and neem leaf powder to the NBG does not influence any changes on its structure of NBG. Figure 2 shows the FTIR spectra of the synthesised samples (NBG, SNBG, and NNBG). The chemical group, along with the respective frequencies, is given in Table 2. The bands observed at 999, 804, and $473 \mathrm{~cm}^{-1}$ correspond to asymmetric and symmetric stretching mode of $\mathrm{Si}-\mathrm{O}-\mathrm{Ca}$ bonds and stretching vibration of $\mathrm{Si}-\mathrm{O}-\mathrm{Si}$ bonds, respectively [22]. A typical absorption band observed at 606 and $566 \mathrm{~cm}^{-1}$ corresponds to phosphate $\left(\mathrm{PO}_{3}{ }^{2-}\right)$ group $[22,23]$. The broad band observed at 1649 and $1384 \mathrm{~cm}^{-1}$ corresponds to $\mathrm{O}-\mathrm{H}$ bending vibration of the chemically adsorbed hydroxyl groups on the glass matrix. Hence, silver (SNBG) and neem (NNBG) doped bioactive glass particles are confirmed by their existing wave number of corresponding functional groups [24]. The presence of terpenoid groups $(\mathrm{C}=\mathrm{C}$ group and geminal methyl group) in the neem samples $1600 \mathrm{~cm}^{-1}$ and $1380 \mathrm{~cm}^{-1}$ which are overlapped with the $\mathrm{O}-\mathrm{H}$ bending vibration [25] confirms the doping of neem with the base glass which are different from other inorganic glass nanocomposites.
The size and shape of the prepared bioactive glass nanoparticles are confirmed by TEM analysis (Figure 3 ). The observed result reveals that the particle size of all glasses is less than $50 \mathrm{~nm}$ with uniform spherical morphology. SNBG and NNBG samples show uniform spherical morphology when compared with NBG. Moreover, the selected area electron diffraction pattern (inset in Figure 3) confirms the amorphous nature of the bioactive glass nanoparticles.

The SEM images of the prepared NBG, SNBG, and NNBG samples before in vitro studies are shown in Figures 4(a)I, 4(b)I, and 4(c)I, respectively. A bundle of needle shaped surface (Figure 4(a)I) with an irregular morphology is obtained for NBG when compared with SNBG (Figure 4(b)I) and NNBG (Figure 4(c)I) samples. On the other hand, the surface of SNBG and NNBG samples shows, respectively, flake (Figure 4(b)I) and spherical (Figure 4(c)I) morphology. A good spherical morphology with uniform particle size is observed in NNBG samples with slight agglomeration. Moreover, the needle shaped morphology is modified to spherical when the neem particle is doped into glass matrix despite the fact that it does not influence their crystalline structure as observed from XRD pattern. This may be due to the presence of amorphous neem particles and also it reduces the particle size of the glass composite negligibly. Table 1 summarises the quantitative analysis (wt\%) of the prepared bioactive glass nanoparticles, which is obtained from the XRF studies. The percentage of composition of elements present and the weight percentage of the designed and experimentally obtained values are compared. The results show $99 \%$ purity with negligible carbon content. 


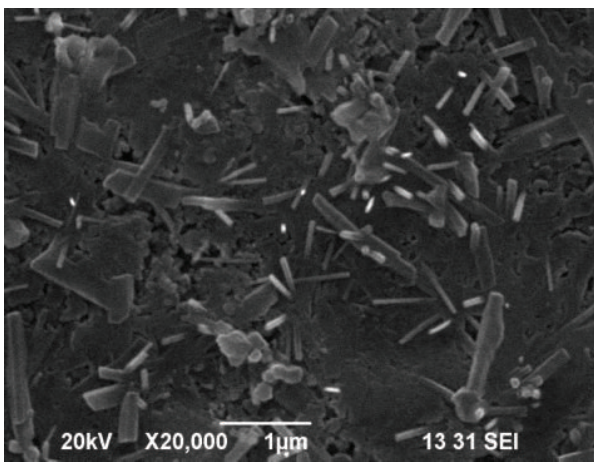

(I) Before in vitro studies

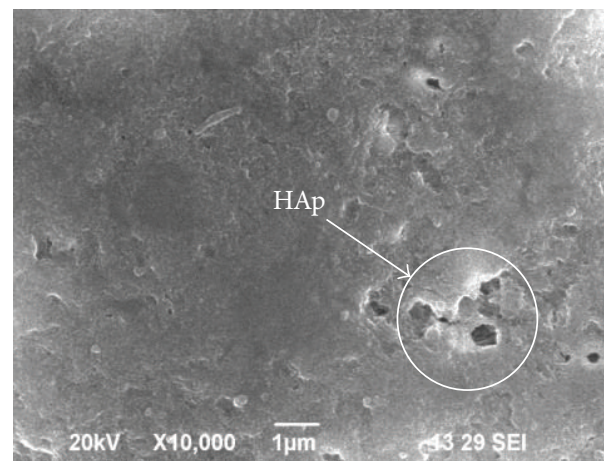

(II) After in vitro studies

(a) NBG

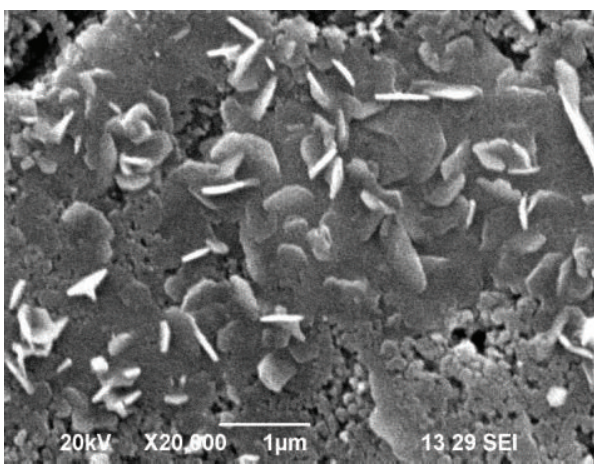

(I) Before in vitro studies

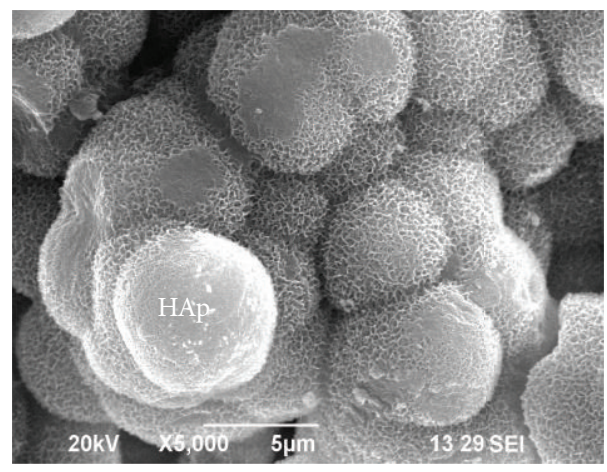

(II) After in vitro studies

(b) SNBG

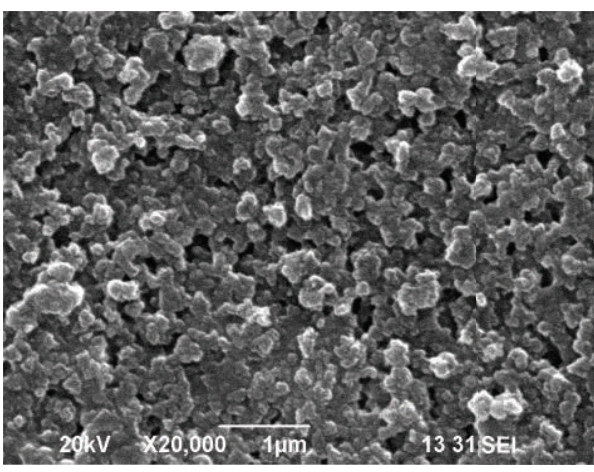

(I) Before in vitro studies

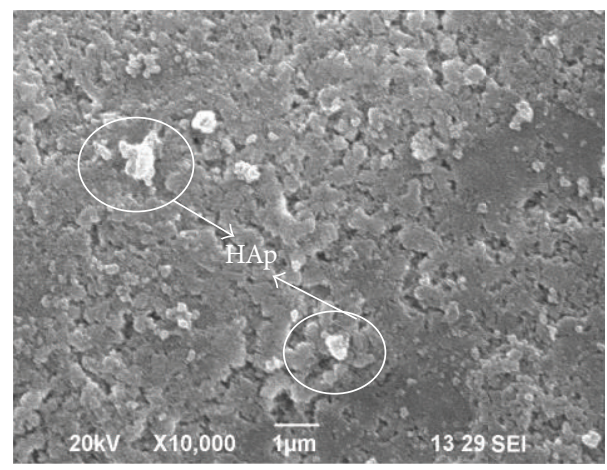

(II) After in vitro studies

(c) NNBG

FIGURE 4: SEM images of silver and neem doped nanobioactive glass particles before and after in vitro studies.

TABLE 1: Compositions of prepared bioactive glass nanoparticles through XRF analysis.

\begin{tabular}{lccccccccc}
\hline \multirow{2}{*}{ Sample code } & \multicolumn{4}{c}{ Designed (wt\%) } & \multicolumn{4}{c}{ Experimental (wt\%) } \\
& $\mathrm{SiO}_{2}$ & $\mathrm{CaO}$ & $\mathrm{P}_{2} \mathrm{O}_{5}$ & $\mathrm{Ag}_{2} \mathrm{O}$ & $\mathrm{Neem} \mathrm{powder}_{2}$ & $\mathrm{SiO}_{2}$ & $\mathrm{CaO}_{2}$ & $\mathrm{P}_{2} \mathrm{O}_{5}$ & $\mathrm{Ag}_{2} \mathrm{O}$ \\
\hline $\mathrm{BG}$ & 58 & 33 & 9 & 0 & 0 & 59.23 & 36.440 & 4.33 \\
SNBG & 58 & 32 & 9 & 1 & 0 & 63.58 & 30.67 & 4.72 \\
NNBG & 58 & 32 & 9 & 0 & 1 & 58.07 & 36.54 & 5.31 & 0 \\
\hline
\end{tabular}


TABLE 2: Analysis of FTIR spectra of the bioactive glass nanoparticles.

\begin{tabular}{|c|c|c|c|c|c|c|c|}
\hline \multicolumn{8}{|c|}{ Wavenumbers $\left(\mathrm{cm}^{-1}\right)$} \\
\hline \multicolumn{3}{|c|}{ Before in vitro } & \multicolumn{3}{|c|}{ After in vitro } & \multirow[t]{2}{*}{ Peak assignments } & \multirow[t]{2}{*}{ References } \\
\hline NBG & SNBG & NNBG & NBG & SNBG & NNBG & & \\
\hline 473 & 473 & - & - & - & - & $\mathrm{Si}-\mathrm{O}-\mathrm{Si}$ stretching & {$[22]$} \\
\hline 566 & 566 & 566 & 570 & 570 & 570 & $\mathrm{PO}_{3}{ }^{-2}$ vibration band & [22] \\
\hline 606 & 606 & 606 & 607 & 607 & 607 & $-\mathrm{P}=\mathrm{O}$ bending band, $\mathrm{PO}_{4}^{-3}$ vibration band & {$[22,23]$} \\
\hline 804 & 804 & 804 & 807 & 807 & 807 & Symmetric $\mathrm{Si}-\mathrm{O}-\mathrm{Si}$ stretching in $\mathrm{SiO}_{4}$ tetrahedron & {$[22]$} \\
\hline- & - & - & 876 & 876 & 876 & $\mathrm{C}-\mathrm{O}$ stretching vibration band in $\mathrm{CO}_{3}{ }^{2-}$ & {$[28,29]$} \\
\hline 999 & 999 & 999 & 1084 & 1084 & 1084 & Asymmetric $\mathrm{Si}-\mathrm{O}-\mathrm{S}$ stretching in $\mathrm{SiO}_{4}$ tetrahedron & {$[22]$} \\
\hline 1384 & 1384 & 1384 & - & - & - & $\mathrm{O}-\mathrm{H}$ bending vibration band & {$[22]$} \\
\hline- & - & - & 1420 & 1420 & 1420 & $\mathrm{C}-\mathrm{O}$ stretching vibration band in $\mathrm{CO}_{3}{ }^{2-}$ & [28] \\
\hline- & - & - & 1472 & 1472 & 1472 & $\mathrm{C}-\mathrm{O}$ stretching vibration band in $\mathrm{CO}_{3}{ }^{2-}$ & [28] \\
\hline 1641 & 1641 & 1641 & 1647 & 1647 & 1647 & $\mathrm{O}-\mathrm{H}$ bending (molecular water) & {$[22]$} \\
\hline
\end{tabular}

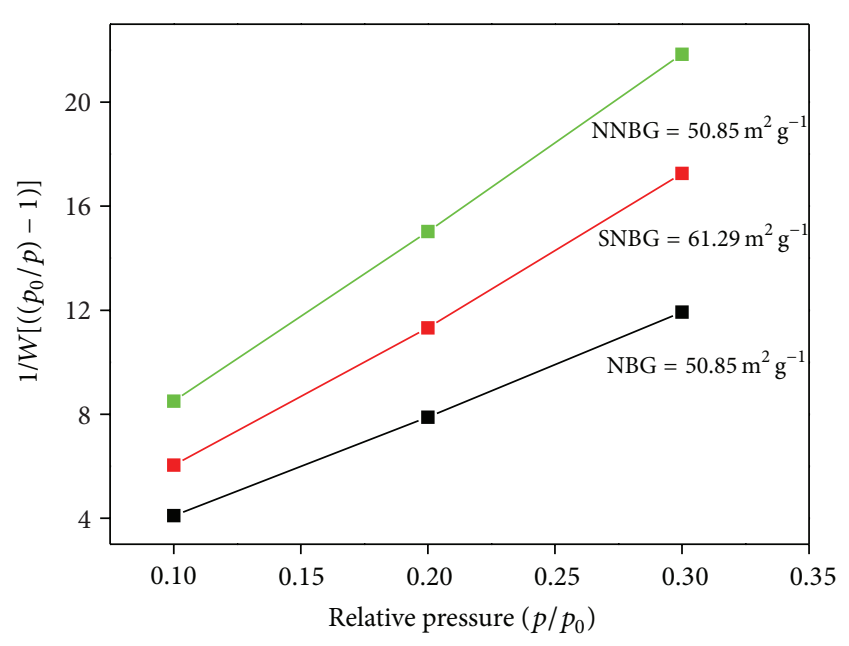

FIGURE 5: BET plot of prepared bioactive glass nanoparticles.

TABLE 3: Elemental analysis of NBG, SNBG, and NNBG sample surfaces after immersion in SBF by XRF.

\begin{tabular}{lccc}
\hline Samples & \multicolumn{3}{c}{ After immersion in SBF } \\
& $\mathrm{Ca}(\mathrm{wt} \%)$ & $\mathrm{P}(\mathrm{wt} \%)$ & $\mathrm{Ca} / \mathrm{P}$ \\
\hline NBG & 38.96 & 18.55 & 2.10 \\
SNBG & 36.74 & 22.82 & 1.60 \\
NNBG & 34.28 & 27.86 & 1.23 \\
\hline
\end{tabular}

Figure 5 shows the BET plot of as-synthesised bioactive glass nanoparticles sintered at $500^{\circ} \mathrm{C}$. The specific surface areas of NBG, SNBG, and NNBG samples are, respectively, $88.94,61.29$, and $50.85 \mathrm{~m}^{2} \mathrm{~g}^{-1}$. The addition of neem leaf particles to the NBG reveals lower surface area $\left(50.85 \mathrm{~m}^{2} \mathrm{~g}^{-1}\right)$ than silver doped nanoparticles $\left(61.29 \mathrm{~m}^{2} \mathrm{~g}^{-1}\right)$, while comparing the NBG $\left(88.94 \mathrm{~m}^{2} \mathrm{~g}^{-1}\right)$. The bioactivity of the glass nanoparticles, where the formation of apatite takes place, depends not only on their composition but also on the surface properties [26].

The variation in the $\mathrm{pH}$ value of the SBF at different immersion intervals for all glass samples is shown in Figure 6.

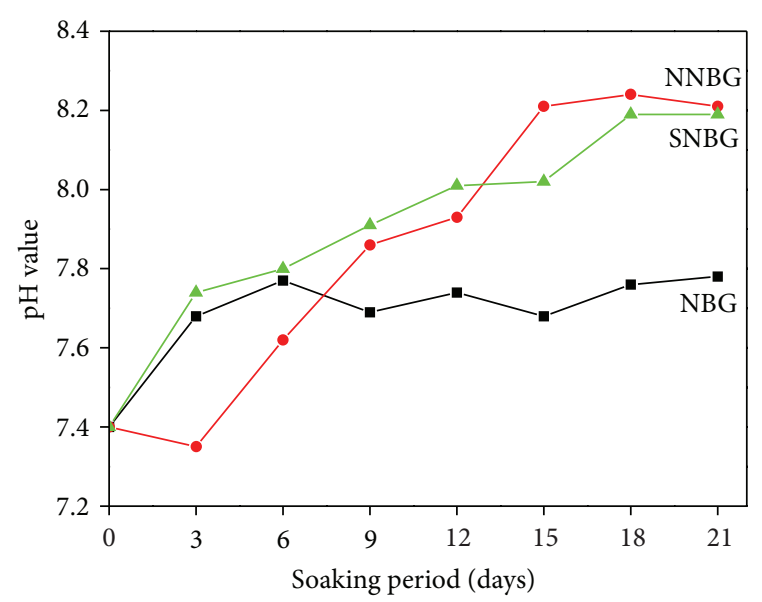

FIGURE 6: $\mathrm{pH}$ value as a function of soaking period in SBF.

The observed changes in all the samples are due to ion exchange that takes place between the samples and SBF. The NBG and SNBG samples show an increase in the $\mathrm{pH}$ value on the third day, whereas NNBG sample reveals a decrease in $\mathrm{pH}$ value due to the faster dissolution of hydrophilic starch and cellulose in neem leaf powder. After the third day, the $\mathrm{pH}$ value of all samples gradually increases up to the 15th day which may be due to more absorption of supplementary ions and sufficient use of $\mathrm{OH}^{-}$ions from the SBF for HAp layer formation on the glass surface. On the other hand, the deposition of saturated $\mathrm{PO}_{4}{ }^{3-}$ and $\mathrm{Ca}^{2+}$ ions on the glass particles influences the $\mathrm{pH}$ value to remain constant after 18th day which is correlated with the previous study [27]. After incubation in SBF, the sample pellets are collected and again characterised using XRD, FTIR, and SEM to ensure the HAp layer formation on the glass surface.

The observed weight loss percentage values of NBG, SNBG, and NNBG samples in the SBF are, respectively, $16.26,12.83$, and $18.56 \%$ (Figure 7 ). NNBG shows an increase in weight loss percentage (18.56\%) compared with NBG and SNBG, which may be due to hydrophilic nature of carbohydrate content (starch and cellulose, the main 


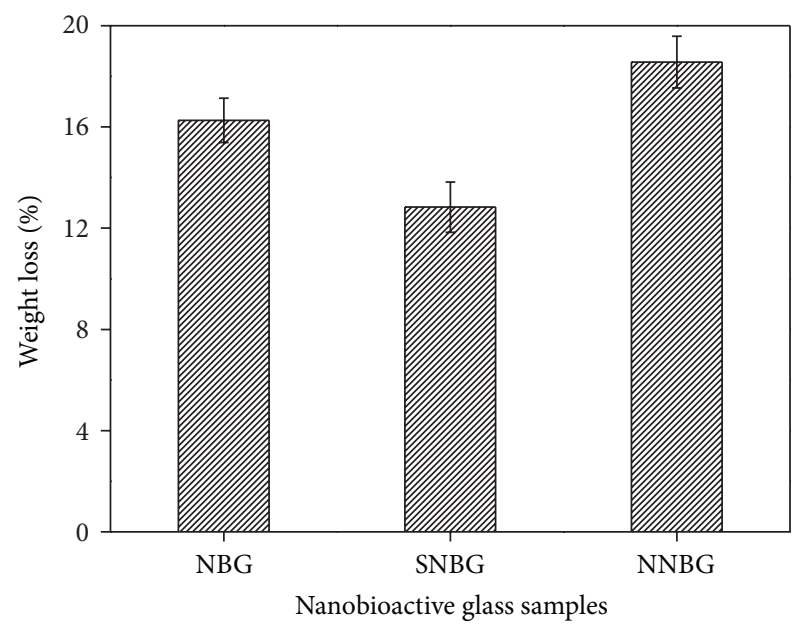

FIGURE 7: Weight loss percentage of bioactive glass samples after 21 days of incubation in SBF.

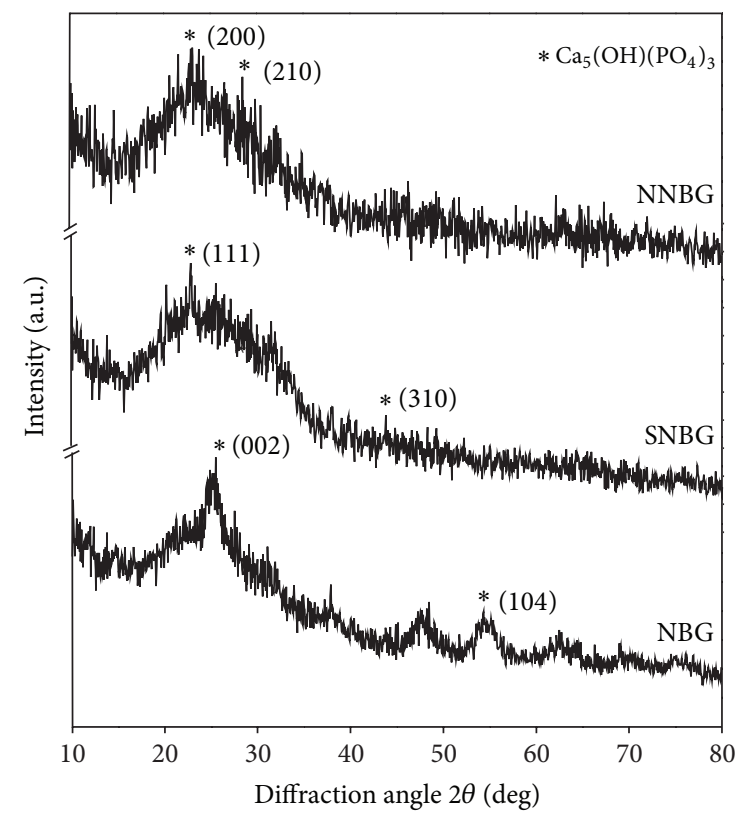

FIGURE 8: XRD pattern of bioactive glass nanoparticles after in vitro studies.

constituent in neem leaf) present in the NNBG sample [24]. The observed decrease in weight loss percentage (12.83\%) in SNBG compared to NBG is due to substitution of $\mathrm{Ag}_{2} \mathrm{O}$ for $\mathrm{CaO}$, which decreases the degradability of glass and may delay the formation of apatite layer on the glass surface [28].

Figure 8 shows the XRD patterns of NBG, SNBG, and NNBG samples after 21 days of in vitro studies. The peaks

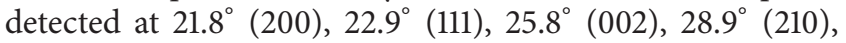
$39.8^{\circ}$ (310), and $54.4^{\circ}$ (104) represent HAp crystalline (JCPDS file number 09-0432) phase over the amorphous glass surface. These results indicate that a strong formation of HAp layer is observed with the NBG and SNBG samples when compared with neem doped glasses. For the NNBG sample, the dissolution rate is suppressed in SBF and acts as an

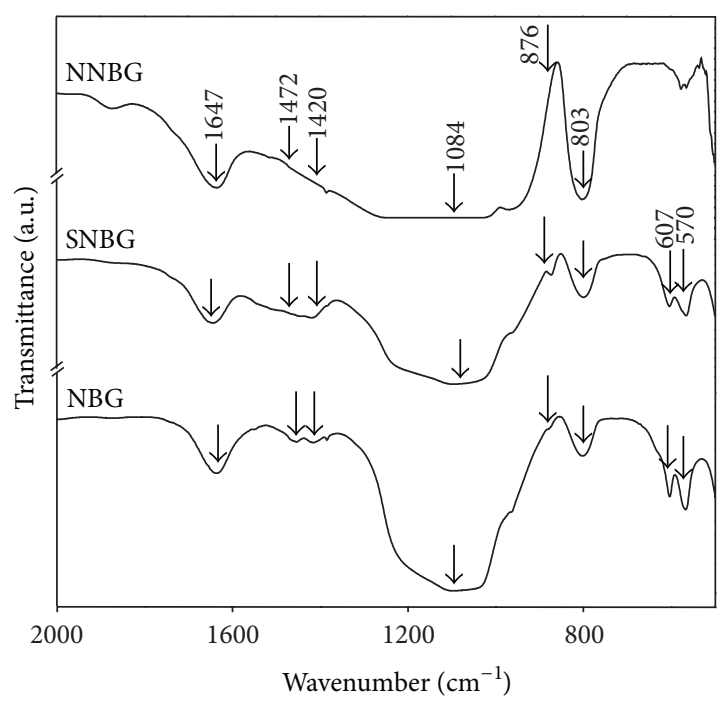

FIGURE 9: FTIR spectra of bioactive glass nanoparticles after in vitro studies.

intermediate oxide in the glass samples whereas silver ions influence the low dissolution rate with poor biological properties.

The observed FTIR spectra of NBG, SNBG, and NNBG samples after immersion in SBF for 21 days are shown in Figure 9 and the peak assignments are given in Table 2. The bands observed at 607 and $570 \mathrm{~cm}^{-1}$ correspond to crystalline phase of phosphate $\left(\mathrm{PO}_{4}{ }^{3-}\right)$ group [22, 23]. In addition, the peaks observed at 1472,1420 , and $876 \mathrm{~cm}^{-1}$ indicate the formation of carbonate apatite $[29,30]$. However, it shows that the HAp layer formation is well observed in the SNBG sample when compared with NNBG sample, due to quick dissolution of $\mathrm{Ca}^{2+}$ and $\mathrm{P}^{5+}$ ions on the surface. This observation shows that SNBG has good bioactivity, as evident from the XRD pattern.

The SEM images of NBG, SNBG, and NNBG samples after 21 days of immersion in SBF are shown in Figures 4(a)II, 4(b)II, and 4(c)II, respectively. The morphological difference is evident in all samples before and after in vitro studies (Figure 4). The morphology of NBG appears as light white precipitate because the glass surface is fully reacted in SBF (Figure 4(a)II). Spherical apatite crystals are formed on the surface of the NNBG sample which is confirmed from Figure 4(c)II. The formation of flake like HAp layer is observed on SNBG (Figure 4(b)II), which is in line with the earlier results [31]. These results confirm that the high reactivity of SNBG in SBF shows better in vitro bioactivity than the NBG and NNBG samples.

The formation of HAp layer on the surface of glass samples is also revealed through XRF analysis. The observed $\mathrm{XRF}$ results for the glass surfaces after immersion in SBF are given in Table 3 . The above results confirm that the surface content of $\mathrm{Ca}^{2+}$ and $\mathrm{P}^{5+}$ increases, whereas the content of $\mathrm{Si}^{4+}$ decreases after immersion in SBF for a period of 21 days. After 21 days, the SNBG composite reveals the $\mathrm{Ca} / \mathrm{P}$ ratio as 1.60 , which is in close agreement with the standard stoichiometric value of HAp (1.67). The above result confirms 


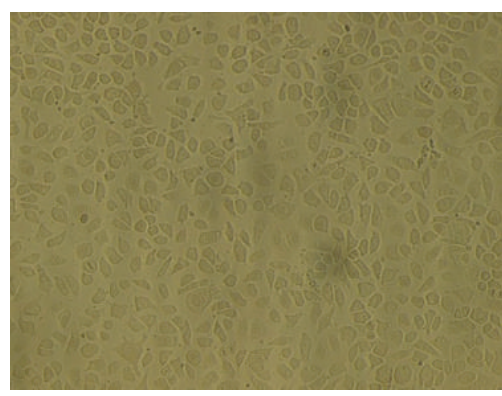

$20 \mu \mathrm{g} \mathrm{mL}^{-1}$

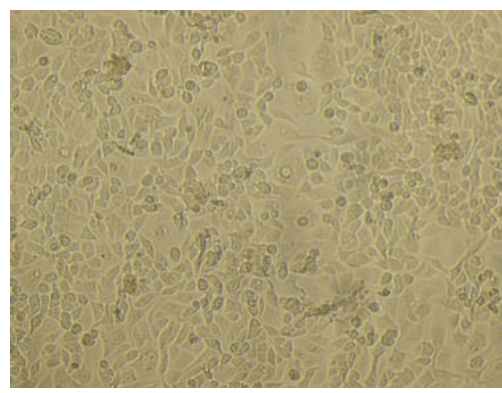

$20 \mu \mathrm{g} \mathrm{mL}^{-1}$

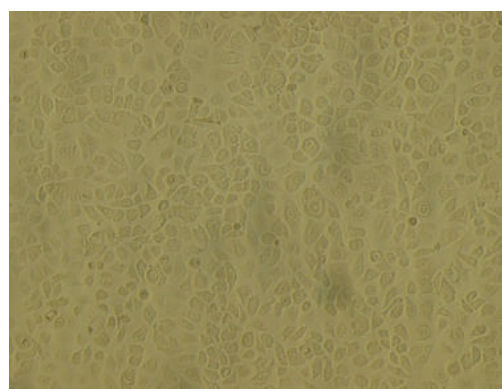

$20 \mu \mathrm{g} \mathrm{mL}^{-1}$

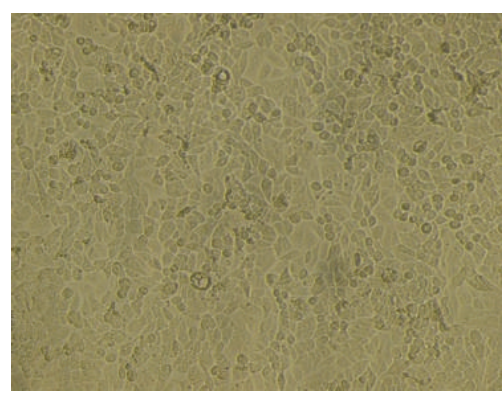

$100 \mu \mathrm{g} \mathrm{mL}^{-1}$

(a) NBG

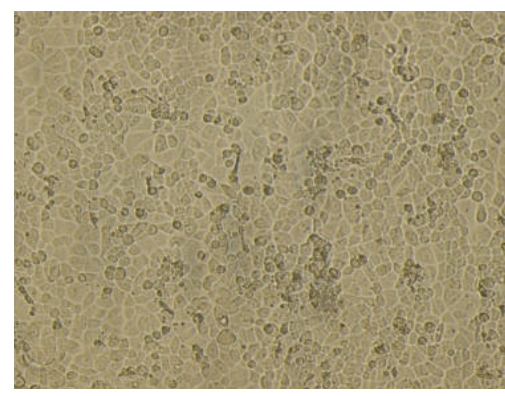

$100 \mu \mathrm{g} \mathrm{mL}^{-1}$

(b) $\mathrm{SNBG}$

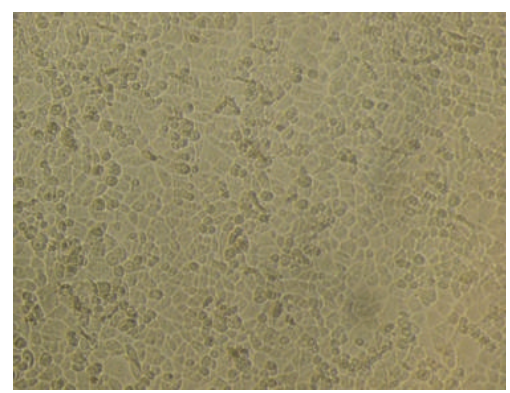

$100 \mu \mathrm{g} \mathrm{mL}^{-1}$

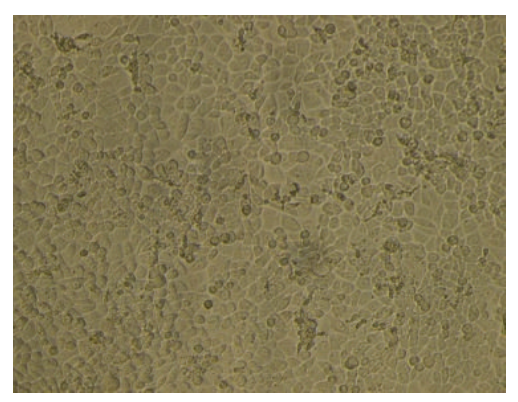

$500 \mu \mathrm{g} \mathrm{mL}^{-1}$

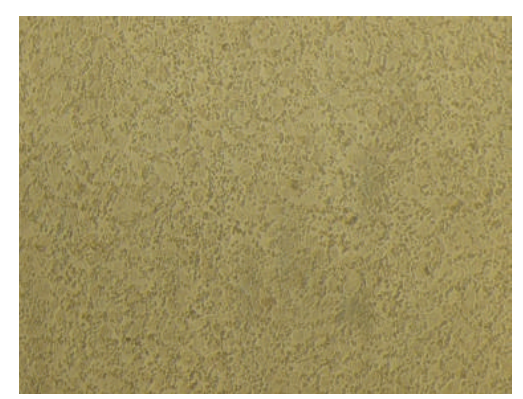

$500 \mu \mathrm{g} \mathrm{mL}^{-1}$

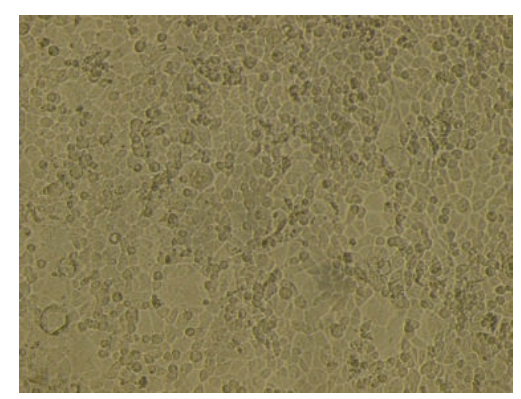

$500 \mu \mathrm{g} \mathrm{mL}^{-1}$

(c) NNBG

FIGURE 10: Morphological responses of AGS cell lines exposed to different concentrations of nanocomposites.

TABLE 4: Antimicrobial effect of bioactive glass nanocomposites against clinical pathogens.

\begin{tabular}{lcccc}
\hline \multirow{2}{*}{ Serial number } & \multirow{2}{*}{ Organisms } & \multicolumn{3}{c}{ Zone of inhibition $(\mathrm{mm})$} \\
& & NBG & SNBG & NNBG \\
\hline 1 & Staphylococcus aureus & - & 8 & 23 \\
2 & Escherichia coli & - & 7 & 23 \\
\hline
\end{tabular}

that the formation of HAp layer on the surface of SNBG sample was high when compared with NBG and NNBG samples.

The antimicrobial effect of the NBG, SNBG, and NNBG samples is assessed by the observed zone of inhibition against $S$. aureus and E. coli, as given in Table 4. The NBG sample shows no zone of inhibition against both organisms. The zone of inhibition for the NNBG sample is found to be $23 \mathrm{~mm}$ against both bacteria. However, the SNBG sample shows the zone of inhibition as 8 and $7 \mathrm{~mm}$ against $S$. aureus and $E$. coli, respectively. From the results, it is inferred that neem added glass nanoparticles reveal good antimicrobial activity against Gram-negative and Gram-positive bacteria when compared with silver doped glasses. The observed broad spectrum antibacterial effect exerted by NNBG is superior to SNBG, which is advantageous for clinical applications. Generally, metal/metal oxide doped bioactive glasses are used to confer antimicrobial action for tissue engineering applications [32, 33]. However, in this study, natural source is attempted to replace conventional metal/metal oxide sources as dopant to develop potent antimicrobial agent's doped bioactive glass for clinical applications. The above studies indicate that the SNBG sample shows better in vitro bioactivity than the NNBG sample. Thus, using medicinally important botanicals such as neem for the construction of efficient biomaterials, NNBG is less attractive due to its bioactivity. 


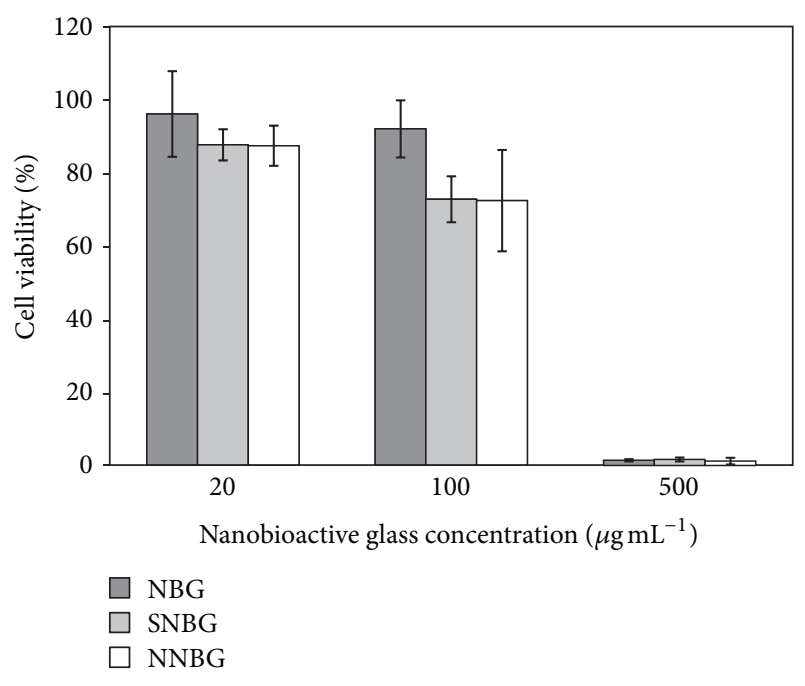

FIGURE 11: Cell viability percentage of AGS cells treated with nanobioactive glass samples.

Biocompatibility of the prepared nanobioactive glass composites is screened using human adenogastric sarcoma (AGS) cell line. Morphological changes due to the treatment with glass nanocomposites are microscopically observed and are shown in Figure 10. From the result, it is inferred that, as the dosage concentration of nanocomposites in the cell vials increases from 20 to $500 \mu \mathrm{g} \mathrm{mL}^{-1}$, the decrease in cell growth and proliferation are observed by the formation of cell aggregation. Similarly, the cell viability percentage is analysed by MTT assay which exhibits a decrease in cell viability with an increase in glass concentration of all the samples (Figure 11). A decrease in cell viability is found in silver and neem doped glasses when compared with base glass at a concentration of 100 to $500 \mu \mathrm{g} \mathrm{mL}^{-1}$. It is also interesting to note that the in vitro biocompatibility of neem doped bioactive glass exhibits enhanced biological responses against AGS cell when compared to silver doped glass samples. The observed results indicate that neem causes only a moderate cell death while doping with base glass samples. This may be due to the fact that neem does not affect the human cells despite the fact that it has potent anticancerous and apoptotic activities. It is also in close agreement with other reported results on the anticancerous activity of the neem against human cell lines [34, 35]. Moreover, in vitro antibacterial property of the neem does not get altered while doping with base glass. Thus, neem doped nanobioactive glass samples can be used as a potent biomaterial for tissue engineering applications.

\section{Conclusion}

Bioactive glass nanoparticles in the system of $58 \mathrm{SiO}_{2}-33 \mathrm{CaO}-$ $9 \mathrm{P}_{2} \mathrm{O}_{5}$ doping with neem (Azadirachta indica) leaf powder and silver are obtained by the sol-gel method. The prepared glass samples reveal amorphous phase, spherical morphology with a particle size of less than $50 \mathrm{~nm}$. The SSA was found in the range of $50.85-88.94 \mathrm{~m}^{2} \mathrm{~g}^{-1}$. The in vitro bioactivity and antimicrobial activity for NNBG and SNBG are studied and compared with NBG sample. The results evidenced that the HAp layer formation is more in NBG and SNBG than in NNBG. In contrast, the antimicrobial study reveals that NNBG has good antibacterial activity against $S$. aureus and E. coli compared with SNBG. In addition, biocompatibility test against human gastric adenocarcinoma cell line also substantiates the better biocompatibility in NNBG at lower concentration. From the bioactivity and antimicrobial activity results, it is concluded that NNBG could be potential candidate for tissue engineering applications because of its excellent antimicrobial and in vitro biocompatibility properties.

\section{Conflict of Interests}

The authors declare that they have no conflict of interests.

\section{Acknowledgment}

The authors acknowledge the financial support from the Department of Science and Technology, New Delhi, to carry out this research project (SR/S2/CMP-0054/2009 dt. 27.09.2010).

\section{References}

[1] M. Bosetti and M. Cannas, "The effect of bioactive glasses on bone marrow stromal cells differentiation," Biomaterials, vol. 26, no. 18, pp. 3873-3879, 2005.

[2] L. L. Hench, "Genetic design of bioactive glass," Journal of the European Ceramic Society, vol. 29, no. 7, pp. 1257-1265, 2009.

[3] H. W. Kim, J. H. Song, and H. E. Kim, "Bioactive glass nanofiber-collagen nanocomposite as a novel bone regeneration matrix," Journal of Biomedical Materials Research A, vol. 79, no. 3, pp. 698-705, 2006.

[4] V. Mortazavi, M. Mehdikhani Nahrkhalaji, M. H. Fathi, S. B. Mousavi, and B. Nasr Esfahani, "Antibacterial effects of solgel-derived bioactive glass nanoparticle on aerobic bacteria," Journal of Biomedical Materials Research A, vol. 94, no. 1, pp. 160-168, 2010.

[5] M. Prabhu, K. Kavitha, P. Manivasakan, V. Rajendran, and P. Kulandaivelu, "Synthesis, characterization and biological response of magnesium-substituted nanobioactive glass particles for biomedical applications," Ceramics International, vol. 39, no. 2, pp. 1683-1694, 2013.

[6] M. Prabhu, K. Kavitha, R. Suriyaprabha, P. Manivasakan, V. Rajendran, and P. Kulandaivelu, "Preparation and characterization of silver-doped nanobioactive glass particles and their in vitro behaviour for biomedical applications," Journal of Nanoscience and Nanotechnology, vol. 13, no. 8, pp. 5327-5339, 2013.

[7] A. M. El-Kady, A. F. Ali, R. A. Rizk, and M. M. Ahmed, "Synthesis, characterization and microbiological response of silver doped bioactive glass nanoparticles," Ceramics International, vol. 38, no. 1, pp. 177-188, 2012.

[8] A. M. El-Kady and A. F. Ali, "Fabrication and characterization of $\mathrm{ZnO}$ modified bioactive glass nanoparticles," Ceramics International, vol. 38, no. 2, pp. 1195-1204, 2012. 
[9] A. Balamurugan, G. Balossier, J. Michel et al., "Sol gel derived $\mathrm{SiO}_{2}-\mathrm{CaO}-\mathrm{MgO}-\mathrm{P}_{2} \mathrm{O}_{5}$ bioglass system-preparation and in vitro characterization," Journal of Biomedical Materials Research B: Applied Biomaterials, vol. 83, no. 2, pp. 546-553, 2007.

[10] M. A. Ouis, "Effect of $\mathrm{ZnO}$ on the bioactivity of Hench's derived glasses and corresponding glass-ceramic derivatives," Silicon, vol. 3, no. 4, pp. 177-183, 2011.

[11] F. N. Oktar, S. Agathopoulos, L. S. Ozyegin et al., "Mechanical properties of bovine hydroxyapatite (BHA) composites doped with $\mathrm{SiO}_{2}, \mathrm{MgO}, \mathrm{Al}_{2} \mathrm{O}_{3}$, and $\mathrm{ZrO}_{2}$," Journal of Materials Science: Materials in Medicine, vol. 18, no. 11, pp. 2137-2143, 2007.

[12] P. Saravanapavan and L. L. Hench, "Low-temperature synthesis, structure, and bioactivity of gel-derived glasses in the binary $\mathrm{CaO}-\mathrm{SiO}_{2}$ system," Journal of Biomedical Materials Research A, vol. 54, pp. 608-618, 2001.

[13] D. C. Greenspan, J. P. Zhong, and D. L. Wheeler, "Bioactivity and biodegradability: melt vs solgel derived bioglass in vitro and in vivo," Bioceramics, vol. 11, p. 345, 1998.

[14] S. Lee, U. Otgonbayar, J. Lee, K. Kim, and K. Kim, "Silver ionexchanged sodium titanate and resulting effect on antibacterial efficacy," Surface and Coatings Technology, vol. 205, no. 1, pp. S172-S176, 2010.

[15] J. Husheng, H. Wensheng, W. Liqiao, X. Bingshe, and L. Xuguang, "The structures and antibacterial properties of nano$\mathrm{SiO}_{2}$ supported silver/zinc-silver materials," Dental Materials, vol. 24, no. 2, pp. 244-249, 2008.

[16] J. R. J. Delben, O. M. Pimentel, M. B. Coelho et al., "Synthesis and thermal properties of nanoparticles of bioactive glasses containing silver," Journal of Thermal Analysis and Calorimetry, vol. 97, no. 2, pp. 433-436, 2009.

[17] W. C. Sarmiento, C. C. Maramba, and M. L. M. Gonzales, "An In-Vitro Study on the antibacterial effect of neem (Azadirachta indica) leaf extract on methicillin-sensitive and methicillinresistant Staphylococcus aureus," PIDSP, vol. 12, pp. 40-45, 2011.

[18] K. Biswas, I. Chattopadhyay, R. K. Banerjee, and U. Bandyopadhyay, "Biological activities and medicinal properties of neem (Azadirachta indica)," Current Science, vol. 82, no. 11, pp. 13361345, 2002.

[19] D. Shanmuga Priya, R. Suriyaprabha, R. Yuvakkumar, and V. Rajendran, "Chitosan-incorporated different nanocomposite HPMC films for food preservation," Journal of Nanoparticle Research, vol. 16, article 2248, 2014.

[20] T. Kokubo and H. Takadama, "How useful is SBF in predicting in vivo bone bioactivity?" Biomaterials, vol. 27, no. 15, pp. 29072915, 2006.

[21] A. W. Bauer, W. M. Kirby, J. C. Sherris, and M. Turck, "Antibiotic susceptibility testing by a standardized single disk method," American Journal of Clinical Pathology, vol. 45, no. 4, pp. 493496, 1966.

[22] H. S. Costa, M. F. Rocha, G. I. Andrade et al., "Sol-gel derived composite from bioactive glass-polyvinyl alcohol," Journal of Materials Science, vol. 43, no. 2, pp. 494-502, 2008.

[23] B. D. Boyan, G. Niederaur, K. Kieswetter, and N. C. Leatherbury, "Biodegradable implant material comprising bioactive ceramic," 5977204 A, United States Patent, 1999.

[24] B. Singh, D. K. Sharma, R. Kumar, and A. Gupta, "Development of a new controlled pesticide delivery system based on neem leaf powder," Journal of Hazardous Materials, vol. 177, no. 1-3, pp. 290-299, 2010.

[25] B. S. Siddiqui, F. Afshan, T. Gulzar, and M. Hanif, "Tetracyclic triterpenoids from the leaves of Azadirachta indica," Phytochemistry, vol. 65, no. 16, pp. 2363-2367, 2004.
[26] P. N. de Aza and Z. B. Luklinska, "Effect of glass-ceramic microstructure on its in vitro bioactivity," Journal of Materials Science: Materials in Medicine, vol. 14, no. 10, pp. 891-898, 2003.

[27] E. Y. Kawachi, C. A. Bertran, and L. T. Kubota, "Interface potential of calcium phosphate in simulated body fluid," Biomaterials, vol. 19, no. 24, pp. 2329-2333, 1998.

[28] P. Ducheyne, S. Radin, and L. King, "The effect of calcium phosphate ceramic composition and structure on in vitro behavior. I. Dissolution," Journal of Biomedical Materials Research, vol. 27, no. 1, pp. 25-34, 1993.

[29] P. Manivasakan, V. Rajendran, P. Ranjan Rauta, B. Bandhu Sahu, and B. Krushna Panda, "Synthesis of monoclinic and cubic $\mathrm{ZrO}_{2}$ nanoparticles from zircon," Journal of the American Ceramic Society, vol. 94, no. 5, pp. 1410-1420, 2011.

[30] Y. Zhang and M. Wang, "A new method to probe the structural evolution during the heat treatment of $\mathrm{SiO}_{2}-\mathrm{P}_{2} \mathrm{O}_{5}$ gel glasses," Materials Science and Engineering B, vol. 67, no. 3, pp. 99-101, 1999.

[31] P. Li, C. Ohtsuki, T. Kokubo et al., "Effects of ions in aqueous media on hydroxyapatite induction by silica gel and its relevance to bioactivity of bioactive glasses and glass-ceramics," Journal of Applied Biomaterials, vol. 4, no. 3, pp. 221-229, 1993.

[32] K. C. Kavya, R. Jayakumar, S. Nair, and K. P. Chennazhi, "Fabrication and characterization of chitosan/gelatin $/ \mathrm{nSiO}_{2}$ composite scaffold for bone tissue engineering," International Journal of Biological Macromolecules, vol. 59, pp. 255-263, 2013.

[33] D. Nadeem, M. Kiamehr, X. Yang, and B. Su, "Fabrication and in vitro evaluation of a sponge-like bioactive-glass/gelatin composite scaffold for bone tissue engineering," Materials Science and Engineering C, vol. 33, no. 5, pp. 2669-2678, 2013.

[34] S. Kumar, P. K. Suresh, M. R. Vijayababu, A. Arunkumar, and J. Arunakaran, "Anticancer effects of ethanolic neem leaf extract on prostate cancer cell line (PC-3)," Journal of Ethnopharmacology, vol. 105, no. 1-2, pp. 246-250, 2006.

[35] A. Bose, E. Haque, and R. Baral, "Neem leaf preparation induces apoptosis of tumor cells by releasing cytotoxic cytokines from human peripheral blood mononuclear cells," Phytotherapy Research, vol. 21, no. 10, pp. 914-920, 2007. 

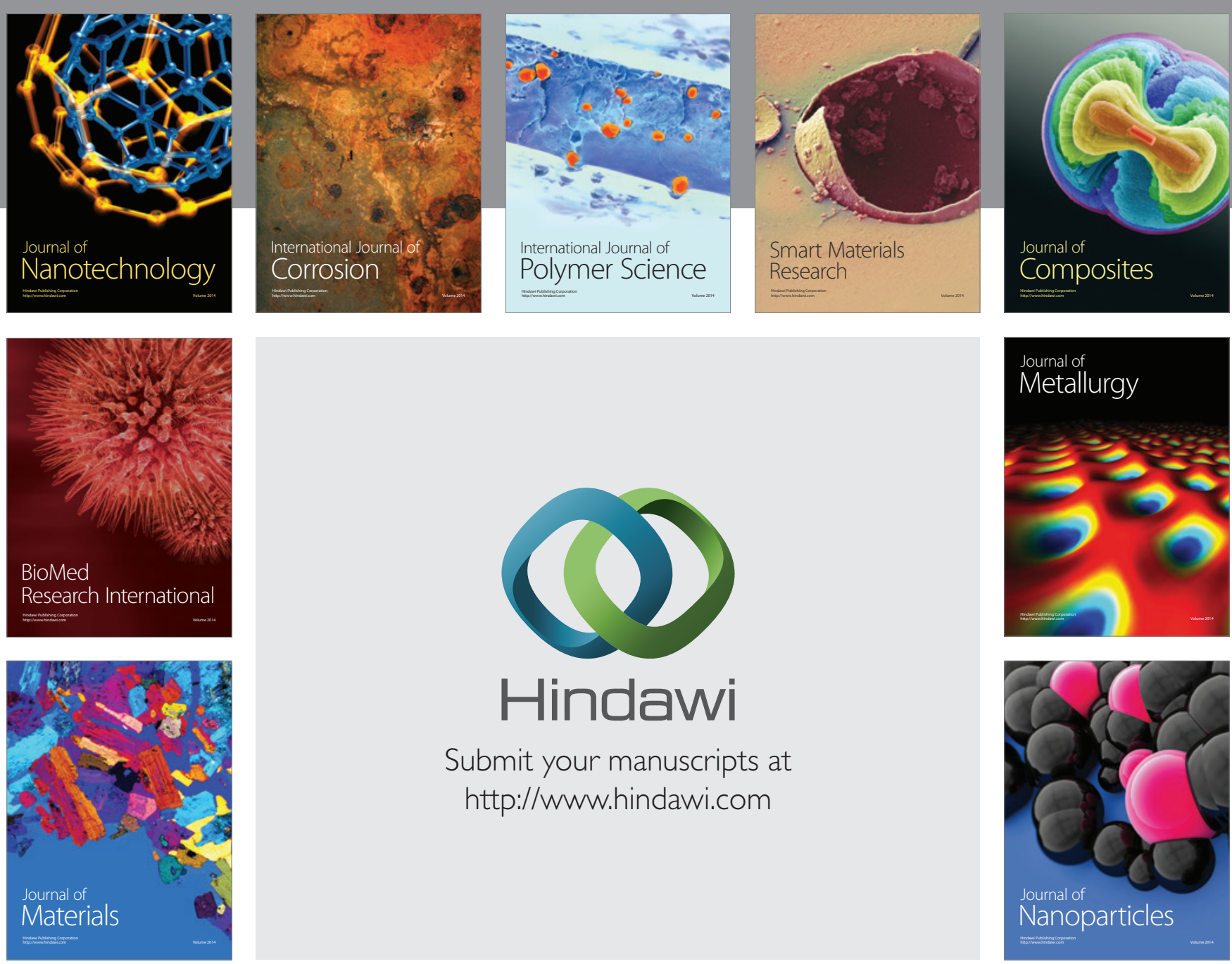

Submit your manuscripts at http://www.hindawi.com
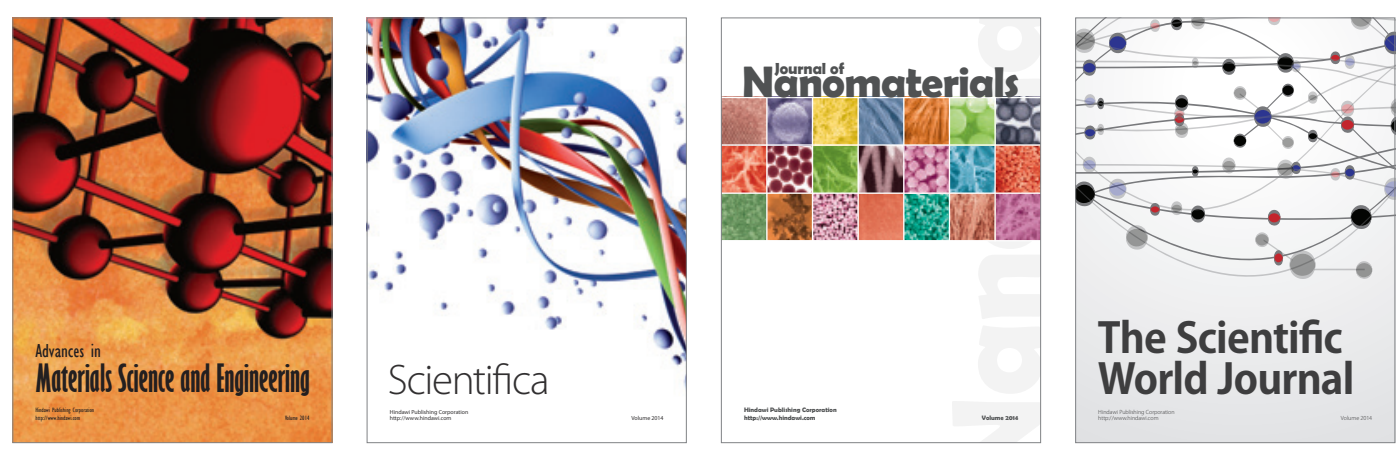

\section{The Scientific World Journal}
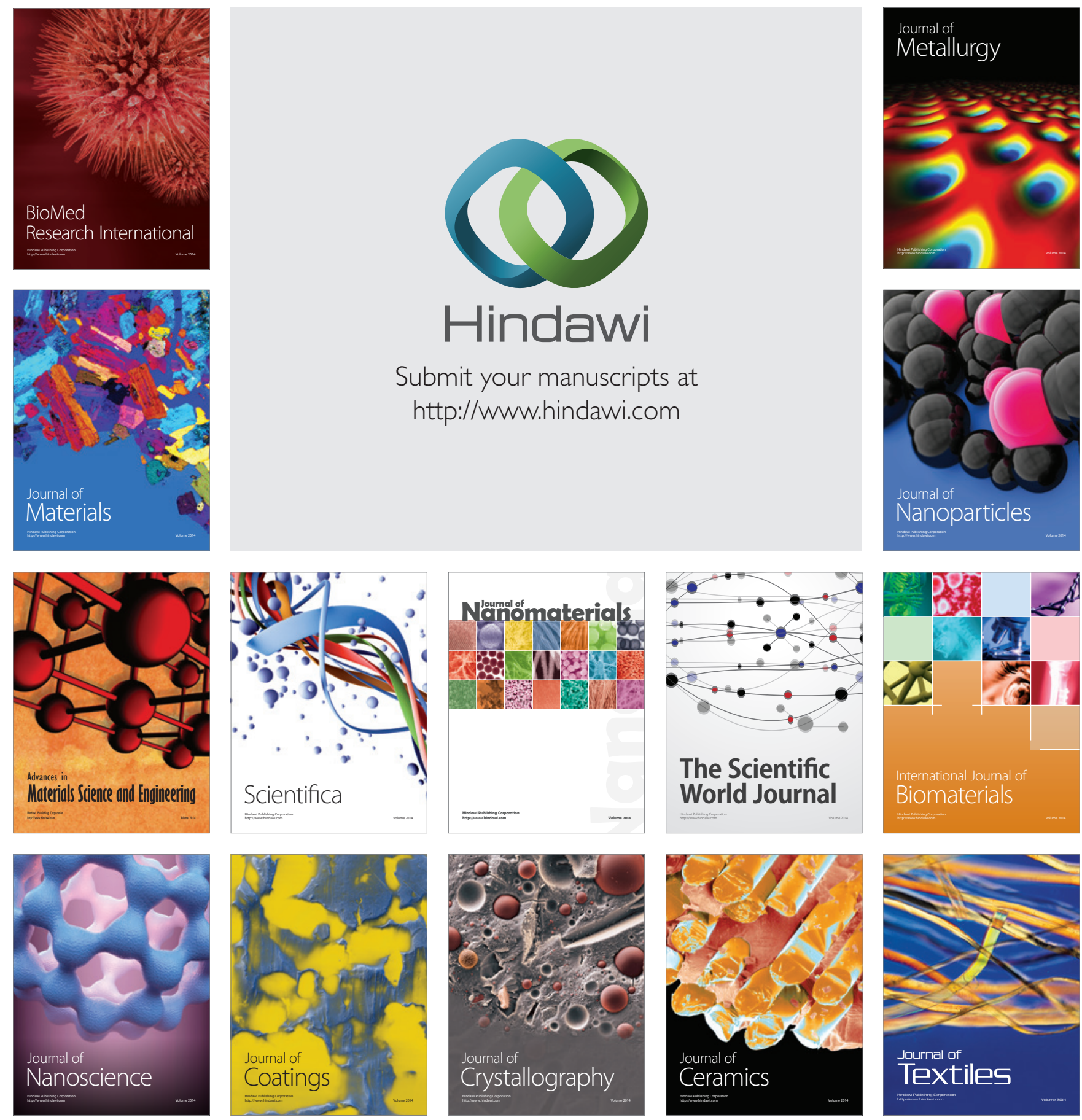